\title{
PLANO COLÔMBIA: securitização do narcotráfico pelos Estados Unidos da América
}

PLAN COLOMBIA: securitization of drug trafficking by the United States of America

\section{Caroline Cordeiro Viana e Silva ${ }^{1}$}

\begin{abstract}
RESUMO
A América Latina vivenciou os reflexos de duas campanhas antidrogas norte-americanas, a Guerra às Drogas e o Plano Colômbia. Tendo isso em vista, o presente trabalho tem como objetivo central comprovar que o tráfico ilícito de drogas permanece com o status de securitizado para os EUA nos anos dois mil. De maneira mais específica, os objetivos são: apresentar a história do combate ao tráfico ilícito de drogas pelo governo norte-americano; apresentar o Plano Colômbia e apresentar a teoria de securitização. Para atingir seus objetivos específicos, optou-se pela proposta teórica de securitização da Escola de Copenhague.
\end{abstract}

Palavras-chave: Plano Colômbia. Securitização. Narcotráfico.

\begin{abstract}
Latin America has experience the reflexed of two north-American Drug campaign, the Drug War and the Plan Colombia. With this in mind this essay has as central objective prove that the drug trafficking in United States of America remains as securitized, at the two thousand years. More specific, the objectives are: Present the history of the fight against drug trafficking by the North-American government; present the Plan Colombia, and present the securitization theory. To achieve the specific objectives, the theoretical choice is securitization of the Copenhagen School.
\end{abstract}

Key-words: Plan Colombia, Securitization, Drug trafficking,

\section{INTRODUÇÃo}

Nos anos 1970 e 1980 é possível perceber um crescimento mundial do consumo de cocaína e maconha, principalmente nos Estados Unidos e na Europa, o que potencializou o tráfico de drogas nos países andinos, transformando negócios ilegais de pequena proporção em empreitadas empresariais. Os principais grupos, neste momento, despontam na Colômbia por acumularem tradição em práticas ilegais, deterem os contatos e conexões para sintetizar a cocaína e transportá-la aos centros consumidores.

\footnotetext{
${ }^{1}$ Mestre em Ciência Política (UFPR), Especialista em Sociologia Política (UFPR), Bacharel em Relações Internacionais (UNICURITIBA). Pesquisadora do Núcleo de Estudos e Pesquisa em Relações Internacionais (NEPRI/UFPR) e professora do Grupo Educacional UNINTER. Curitiba, Brasil.

Conjuntura Global, Vol. 4, n. 2, maio/ago., 2015, p. 124-132. 
Os colombianos concentravam o conhecimento para transformar a pasta-base em cocaína pura e a vendiam em grandes carregamentos internacionais. (RODRIGUES, 2002).

A América Latina como um todo começou a vivenciar os reflexos de tratados internacionais e também, os reflexos de duas campanhas antidrogas norte-americanas, a Guerra às Drogas e o Plano Colômbia. No início dos anos 1970, o presidente norteamericano Richard Nixon identificou as drogas como o inimigo público número um do país, declarando a "Guerra às drogas". Assim, o Estado norte-americano dá rosto e localização ao inimigo: os Estados produtores das drogas consumidas no interior de seu país. 0 inimigo interno agora é, também, uma ameaça internacional, o que é uma importante fundamentação retórica para justificar as ações intervencionistas estadunidenses na América Latina.

O Plano Colômbia foi elaborado em conjunto pelos governos colombiano e americano. Projetado para contar com 7,5 bilhões de dólares, foi aprovado pelo Congresso norte-americano e tinha três componentes principais: I. quatro bilhões de dólares desembolsados pelo governo colombiano para investimentos sociais e substituição de plantios de coca para a população afetada pela violência; II. 1,3 bilhão de dólares desembolsados pelo governo americano para a assistência técnica, militar e financeira para o combate ao tráfico na Colômbia; III. 1,7 bilhão de dólares desembolsados por países europeus para a paz. O Congresso americano aprovou o desembolso de 1,3 bilhão, sendo 860,3 milhões destinados à Colômbia e outros 329 milhões divididos entre Bolívia, Peru e Equador.

Tendo isso em vista, o presente trabalho tem como objetivo central comprovar que o tráfico ilícito de drogas permanece com o status de securitizado para os Estados Unidos da América nos anos dois mil. De maneira mais específica, os objetivos são: apresentar a securitização do tráfico ilícito de drogas pelo governo norte-americano; apresentar o Plano Colômbia; e por fim, comprovar a permanência deste status de securitização nos anos dois mil com o Plano Colômbia. Para atingir seus objetivos específicos, optou-se pela proposta teórica de securitização da Escola de Copenhague. 


\section{A SECURITIZAÇÃO DO TRÁFICO ILEGAL DE DROGAS NOS EUA}

A América Latina como um todo começou a vivenciar os reflexos dos tratados internacionais vistos anteriormente e, também, os reflexos de duas campanhas antidrogas norte-americanas, a Guerra às Drogas e o Plano Colômbia. No início dos anos 1970, o presidente norte-americano Richard Nixon identificou as drogas como o inimigo público número um do país, declarando a "Guerra às drogas". Assim, o Estado norteamericano dá rosto e localização ao inimigo: os Estados produtores das drogas consumidas no interior de seu país. 0 inimigo interno agora é, também, uma ameaça internacional, o que é uma importante fundamentação retórica para justificar as ações intervencionistas estadunidenses na América Latina. (RODRIGUES, 2003).

Em 1986, o presidente norte-americano Ronald Reagan (1980-1988) edita o documento sobre as diretrizes norte-americanas para os narcóticos e a segurança nacional. Esse documento justificou a intervenção estadunidense na América Latina que iniciaria na década de 1980. Desde o governo Reagan, os Estados Unidos têm definido as drogas como um problema de segurança nacional e o ataque a esse problema deveria ser in locus, ou seja, atacar a produção nos países fontes: Bolívia, Colômbia e Peru. (RODRIGUES, 2002).

Combatendo as drogas como um problema de segurança nacional o governo Reagan destinou 61\% de seus recursos administrativos em 1982 à guerra às drogas e 69\% no ano de 1989, chegando, em seus oito anos de governo, a uma média de 66\% dos recursos na redução de oferta de drogas. Adicionalmente as políticas de redução de oferta, o presidente norte americano promoveu outras medidas: Mobilizar as Forças Armadas estadunidenses para atuar em território estrangeiro e a utilização da diplomacia retaliativa, ou seja, aplicação de sanções aos países alvo. Nesse contexto, fuzileiros navais norte-americanos ocuparam a Cidade do Panamá e capturaram o então presidente, Manuel Noriega, acusando-o de conspiração por tráfico de drogas. (VILLA, 2007).

A invasão ao Panamá em 1989 e a captura de Manuel Noriega representou o ponto de inflexão dos Estados Unidos na política de Guerra às Drogas e demonstrou que, a partir de então, os EUA estariam dispostos a utilizar quaisquer meios para o combate ao narcotráfico. 0 tráfico de psicotrópicos ilegais passaria a ser interpretado, pelo 
governo norte-americano, como alvo primordial de sua segurança internacional e passaria a ser combatido com todas as forças, inclusive militares. (VILLA; OSTOS, 2005). Esta política, liderada por George Bush (1989- 1993), inaugurava nova fase nos EUA, fase essa que representava o esforço para militarizar o combate ao narcotráfico no continente.

A ênfase na militarização de George Bush mostrou-se contraproducente. Desse modo, uma readequação programática era necessária. Além disso, a vitória do presidente Bill Clinton em 1992 trazia uma nova abordagem ao narcotráfico. No lugar da militarização, Clinton propõe a responsabilidade compartilhada. Com isso, o combate ao tráfico de drogas ganhou positividade e elevou esse combate ao topo da agenda continental e nacional dos Estados americanos.

Com a iniciativa do governo Bill Clinton, foi realizada, em Miami, a Cúpula das Américas, em dezembro de 1994. Reuniram-se chefes de Estado de todo o continente (exceto Cuba) para discutir o futuro das nações americanas. 0 documento final Pacto para o desenvolvimento e a prosperidade: democracia, livre comércio e desenvolvimento sustentável nas Américas tinha um tópico, um plano de ação, em que um de seus subitens era intitulado "A luta contra o problema das drogas ilícitas e delitos conexos" em que o texto investe em dois principais argumentos: 1) aumento, de cada Estado, na fiscalização sobre transações financeiras suspeitas, unindo forças na interceptação das redes de lavagem de dinheiro; 2) promoção de ações coordenadas entre os Estados para a destruição de organizações do tráfico, substituição dos cultivos ilícitos por culturas alternativas e controle de insumos químicos. (RODRIGUES, 2002).

Com essa nova postura de Clinton, o eixo central da Guerra às Drogas passou a ser conhecido como Estratégia Andina. Essa Estratégia condensa quatro pontos principais: 1) fortalecimento das instituições políticas dos países chaves na oferta de drogas - Bolívia, Colômbia e Peru; 2) fortalecimento operacional de unidades militares e policiais encarregadas do combate ao tráfico; 3) assessoramento militar e policial para o desmantelamento de cartéis e firmas de drogas; 4) assistência comercial e fiscal para minimizar as consequências sociais decorrentes da privação de subsistência advinda do tráfico. (VILLA; OSTOS, 2005).

Com o fim da administração de Clinton e início da administração de George W. Bush em 2001, a Estratégia Andina foi substituída pela Iniciativa Regional Andina que 
previa fundos não apenas para a Colômbia, como também para outros países andinos, além de Brasil e Panamá. Posteriormente renomeado de Iniciativa Andina Antidrogas, o Congresso norte-americano aprovou um orçamento de 700 milhões de dólares para a Iniciativa no ano de 2003 e 731 milhões de dólares no ano de 2004. Esses orçamentos eram divididos entre Estados, 63\% eram destinados aos programas na Colômbia e o restante era dividido entre Peru, Bolívia e Equador. (Id., 2005).

A estratégia traçada por Bush possuía três elementos centrais: prevenção ao uso de drogas, intervenção e recuperação dos usuários e a desarticulação do mercado de substâncias ilícitas. 0 primeiro ponto reconhece que o consumo de drogas faz parte do problema, ou seja, o próprio mercado dos Estados Unidos faz parte do problema, o que representa uma mudança no ponto de vista norte americano, se comparado com a Iniciativa Andina.

\section{O PLANO COLÔMBIA}

Em 1998, ao assumir a presidência colombiana, Andres Pastrana conseguira obter a aprovação de um ambicioso plano, de US\$ 7,5 bilhões (com recursos dos EUA, Europa e comunidade internacional) e juntou a isso seu apoio político interno para iniciar conversas de paz com o principal grupo guerrilheiro, as Forças Armadas Revolucionárias da Colômbia (FARC).

As ações de Pastrana não obtiveram resultado positivo, pois as FARC tomaram de fato o controle da zona desmilitarizada criada por ele para as negociações. Além disso, ao executarem cidadãos americanos, as FARC forçaram os EUA a retirar o apoio à estratégia de Pastrana. Com o objetivo de estabelecer uma política comum nos países andinos contra o narcotráfico da Colômbia e com a falência da iniciativa de Pastrana, o presidente George W. Bush optou por fornecer apoio financeiro. Os EUA voltaram a focar seu investimento apenas no controle do tráfico de drogas e, no ano 2000, o Congresso americano aprovou um orçamento de US\$ 1.3 bilhão para uma das ações da "Guerra às Drogas", o Plano Colômbia. (VILLA; OSTOS, 2005).

O Plano Colômbia foi elaborado em conjunto pelos governos colombiano e americano. Projetado para contar com 7,5 bilhões de dólares, foi aprovado pelo Congresso norte americano e tinha três componentes principais: I. quatro bilhões de 
dólares desembolsados pelo governo colombiano para investimentos sociais e substituição de plantios de coca para a população afetada pela violência; II. 1,3 bilhão de dólares desembolsados pelo governo americano para a assistência técnica, militar e financeira para o combate ao tráfico na Colômbia; III. 1,7 bilhão de dólares desembolsados por países europeus para a paz. 0 Congresso americano aprovou o desembolso de 1,3 bilhão, sendo 860,3 milhões destinados à Colômbia e outros 329 milhões divididos entre Bolívia, Peru e Equador. (VILLA, 2007).

Os pontos estratégicos do Plano eram: I. o processo de paz; II. a economia colombiana; III. O desenvolvimento social e democrático; IV. A luta contra o tráfico de drogas - chamado no Plano de narcotráfico; V. a reforma do sistema judicial e a proteção dos direitos humanos. Segundo Rafael Villa (2007), apesar de ter sido desenvolvido por ambos os governos e de ter a maior iniciativa financeira vindo da Colômbia, o Plano mostrou que os Estados Unidos "alimentavam poucas esperanças de que os países andinos, especialmente a Colômbia, tivessem condições de resolver problemas de produção e tráfico de drogas através de suas instituições nacionais". (VILLA, 2007, p. 58).

Porém, em termos reais, a iniciativa significou: (i) a intensificação da pulverização dos cultivos de maconha, coca e papoula; (ii) a proibição de carregamentos para EUA e Europa; (iii) a extradição de condenados por tráfico e maior vigilância nas fronteiras para frear a movimentação de traficantes. Os países vizinhos à Colômbia passaram a sentir profundamente os reflexos da expansão do conflito colombiano, cuja internacionalização tornou-se institucionalizada pelo Plano Colômbia e pela Iniciativa Andina Antidrogas. O sucesso dessas iniciativas repercute, principalmente, no Peru e na Bolívia, onde o cultivo da coca cresceu como nunca havia crescido antes. Segundo os autores "há evidências de que o conflito na Colômbia seja um foco de irradiação de tensão regional, criando problemas de segurança nas fronteiras com todos os vizinhos (incluindo Brasil e Panamá)". (VILLA; OSTOS, 2005, p. 17).

Percebendo os efeitos colaterais do Plano, a administração de G. W. Bush afirmou que deveria contribuir para acabar com o tráfico, deter as guerrilhas e acabar com a violência que se espalhara por toda a região. Com esta visão um pouco mais global do tema, o governo americano implementou um plano adicional ao Colômbia, a chamada Iniciativa Regional Andina, que posteriormente foi renomeada de Iniciativa Andina 
Antidrogas. Esta nova iniciativa foi aprovada pelo Congresso com um orçamento de 700 milhões de dólares para 2003 e de 731 milhões de dólares para 2004, que seriam divididos para os países andinos, além do Brasil e Panamá. Mas, mesmo com essa nova iniciativa, a maior parte dos recursos foi destinada à Colômbia, que contou com $63 \%$ dos recursos.

Sendo assim, é possível perceber, com esta análise, que o governo norteamericano esteve muito envolvido com o combate a produção e tráfico de drogas na América do Sul, desde o início da guerra as drogas, na década de 1970, até o Plano Colombia nos anos 2000.

\title{
MANUTENÇÃO DO STATUS DE SECURITIZADO
}

Segundo a Escola de Copenhague, qualquer assunto público pode ser alocado no espectro de não politizado, politizado ou securitizado, podendo variar entre eles. Não politizado quando o Estado não é envolvido na questão e não é, em nenhuma forma, uma questão de debate ou decisão pública. Politizado significa que o assunto faz parte da política pública do Estado e requer decisões governamentais, alocação de recursos ou qualquer outra forma de governança. E por securitizada entende-se que a questão é apresentada como uma ameaça existencial, exigindo uma medida de emergência e justificativa para ações fora dos limites normais dos procedimentos políticos. (BUZAN, WAEVER, WILDE, 1998). Ou nas palavras dos autores:

\begin{abstract}
In theory, any public issue can be locate on the spectrum ranging from nonpoliticized (meaning the state does not deal with it and it is not in any other way made an issue of public debate and decision) through politicized (meaning the issue is part of public policy, requiring government decision and resource allocations or, more rarely, some other form of communal governance) to securitized (meaning the issue is presented an existential threat, requiring emergency measures and justifying actions outside the normal bounds of political procedure). (BUZAN, WAEVER, WILDE, 1998, p. 23)²
\end{abstract}

\footnotetext{
${ }^{2}$ Em teoria, qualquer questão pública pode ser localizar no espectro que vai de não politizada (ou seja, o Estado não lida com isso e não é, em qualquer outra forma, uma questão de debate público ou decisão pública) para o politizado (significando que o assunto faz parte da política pública, exigindo decisão do governo e alocação de recursos ou, mais raramente, alguma outra forma de governo comunal) para securitizado (significando que o problema é apresentado como uma ameaça existencial, exigindo medidas de emergência e justifica ações fora dos limites normais de procedimento político).

Conjuntura Global, Vol. 4, n. 2, maio/ago., 2015, p. 124-132. 
A securitização, no início de seu processo, trata-se de uma argumentação sobre o futuro, sobre alternativas futuras, na maioria das vezes hipotéticas e contrafactuais. Os argumentos sempre envolvem duas predições: o que irá acontecer se não for tomada uma ação securitizante e o que ocorrerá se a ação for tomada. Sendo assim, conclui-se que estudos de securitização são basicamente estudos qualitativos.

Levando em consideração essa definição da Escola, é possível perceber que desde o início da Guerra as Drogas até o Plano Colômbia, o governo norte americano apresenta a questão como uma ameaça existencial, exigindo uma medida de emergência e justificativa para ações fora dos limites normais dos procedimentos políticos. Como por exemplo, a iniciativa andina, e claramente com o Plano Colômbia nos anos 2000.

Segundo Rodrigues (2012) em 1995 os EUA continuavam comprovando que o tráfico ilícito de drogas se mantinha com status de securitizado, o documento Presential Decision Directive, intitulado International Organized Crime, destacou o crime organizado como ameaça à segurança do Estado e internacional, afirmando que o narcotráfico era um abalo político-institucional, por te poder econômico. Os norte-americanos exerciam pressão para a ampla aceitação da guerra a drogas pelos países da américa-latina "cada Estado teve um modo particular de incorporar o modelo proibicionista que respondia a dinâmicas internas”. (RODRIGUES, 2012 , p.15)

\footnotetext{
Em suma, a adesão por parte dos países latino-americanos não foi uma mera sujeição à agenda de segurança hemisférica estadunidense. Ao contrário, as intenções dos EUA encontraram pontos de conexão em cada país que aderiu ao proibicionismo. Os Estados latino-americanos não foram, assim, meras marionetes dos interesses geopolíticos estadunidenses traduzidos nas ações da "guerra às drogas". Por isso, alguns deles, como a Colômbia, o México e o Brasil podem ser interessantes laboratórios de análise desse processo de adequação local ao proibicionismo militarista financiado pelos Estados Unidos. (RODRIGUES, 2012, p. 15)
}

Essa ação norte-americana de pressão para a ampla aceitação da guerra as drogas corrobora para a confirmação da manutenção da securitização do narcotráfico pelo governo norte-americano nos anos 2000. O Plano Colômbia demonstra isso por ser uma medida de emergência e com ações fora dos limites normais dos procedimentos políticos - com a aprovação de um orçamento especial para a ação. E também por ser uma ação emergencial pontual. 


\section{CONSIDERAÇÕES FINAIS}

Tendo isso em vista o objetivo geral do presente trabalho, que era comprovar que o tráfico ilícito de drogas permanece com o status de securitizado para os EUA nos anos dois mil. É possível afirmar que o objetivo foi concluído, com a confirmação da hipótese de que o status de securitizado é mantido com a execução do Plano Colômbia. De maneira mais específica, é possível concluir que o trabalho atingiu seus objetivos específicos, o primeiro: apresentar a securitização do tráfico ilícito de drogas pelo governo norte-americano, foi atingido ao ser apresentada a história do combate norteamericano as drogas. 0 segundo objetivo específico foi atingido ao apresentar o Plano Colômbia; e por fim o último objetivo específico foi atingido ao explicar o conceito teóricos de securitização e comprovar a permanência deste status de securitização nos anos dois mil com o Plano Colômbia.

\section{REFERÊNCIAS}

BUZAN, Barry; WAEVER, Ole; WILDE, Jaap de. Security: a new framework for analysis. Boulder: Lynne Reinner Publishers, 1998.

RODRIGUES, Thiago. A Infindável Guerra Americana: Brasil, EUA e o narcotráfico no continente. São Paulo: São Paulo em Perspectiva, vol.16 $\mathrm{n}^{\circ} .2$, abril-jun 2002. 2003.

RODRIGUES, Thiago. Narcotráfico: uma guerra na guerra. São Paulo: Desatino,

RODRIGUES, Thiago. Narcotráfico e Militarização nas américas: Vício de Guerras. CONTEXTO INTERNACIONAL Rio de Janeiro, vol. 34, n 1, janeiro/junho 2012, p. 9-41.

VILLA, Rafael. Quatro teses sobre a política de segurança dos Estados Unidos para a América do Sul. São Paulo: USP, 2007.

VILLA, Rafael Duarte ; OSTOS, Maria del Pilar. As relações Colômbia, países vizinhos e Estados Unidos: visões em torno da agenda de segurança. Revista brasileira de política internacional, vol.48, no.2, 2005. 